\title{
ASSESSMENT OF THE CORIOLIS FORCE IMPACT ON THE OPERATION OF THE TOWER CRANE SWING MECHANISM
}

\author{
Vadim Aleynik ${ }^{1}$, Sergey Repin², Constantine Rulis ${ }^{3}$ \\ 1,2,3 Saint Petersburg State University of Architecture and Civil Engineering, \\ VtorajaKrasnoarmejskajaul.4, St. Petersburg, 190005, Russia \\ 11vadim.aleynik@gmail.com, ${ }^{2}$ repinserge@mail.ru, ${ }^{3}$ rulys52@mail.ru
}

\begin{abstract}
In this paper, issues of the Coriolis force impact on the operation of the tower crane swing mechanism during the starting period under combination of working motions (boom swing and outreach increase) are considered. Quantitative dependencies of the parameters characterizing the mechanism starting mode on the velocity of load trolley travel along the boom and wind load are provided. Diagrams of these dependencies conveniently illustrate a noticeable decrease in the crane output upon adverse combination of factors related to the occurring Coriolis acceleration. More specifically, if the perpendicularly directed heavy wind load influences the boom in case of combination of working motions of the boom swing and outreach change, the starting time constituting the most part of the operating time of the swing mechanism can increase by 20 and more percent. The corresponding methodology of the calculation investigation is also stated in the paper.
\end{abstract}

\section{Keywords}

Swing mechanism calculation, crane mechanism calculation, combination of working motions of the crane, coriolis acceleration, coriolis force

\section{Introduction}

Increase in length of the saddle jib and, therefore, increase of outreach are current trends in development of tower crane designs. At the present time, the maximum outreach value is $60-80$ meters in large models of the leading global manufacturers. Big length of the horizontal boom enables to simplify the operational cycle of the crane through exclusion of one of four types of working motions, i.e. machine rail travel. Simplification of the crane design, improvement of crane stability and decrease in the labor input of pre-construction activities can be noted as accompanying effects. A large range of changes in outreach also implies the increased travel velocity of the load trolley along the boom (up to 120 meters per minute in modern cranes).

It stands to reason that actual operational cycles are accompanied by combination of motions, in particular, of outreach change (travel of the load trolley along the boom) and boom swing. Upon combination of these motions, the load trolley executes a complex motion along a flat spiral in the fixed coordinate system. It is known from the theoretical mechanics course that even at constant relative velocities of the motions being combined such complex motion is accompanied by a secondary force caused by Coriolis acceleration (Polyakhov, 2015; Teplyakov, 2004). In case of combination of swing with outreach increase, this force creates additional resistance to the swing actuator. The known publications (Aleksandrov, 1986; Vainson, 1989; Gokhberg, 1988) dedicated to the subject of crane mechanism calculation do not mention the force caused by Coriolis acceleration. In this regard, the issue of the necessity to take into account this acceleration in the mechanism design methodology appears to be topical. Investigations in which Coriolis acceleration is taken into consideration when solving a problem of decrease in the load sway on fall ropes of the crane lifting tackle are available. Various solutions are proposed: installation of additional elastic linkages and dampers between the boom and the load (La Duc, 2015), implementation of the complex law of variation of the moving force during mechanism speed-up by means of the control system for the 
frequency-regulated drive (Naoki Uchiyama, 2013; Tepliakov, 2004), setting of the optimum value of the angular velocity of boom rotation (A. Perig, 2011). The force caused by Coriolis acceleration is proposed to be taken into account upon calculation for not only cranes but also other machines, e.g. excavators - for turnover stability (A. Kholyavko, 2014), log loader working equipment drives (Kolesnikov, 2013).

\section{Materials and methods}

Coriolis acceleration is numerically equal to twice the product of the angular velocity of rotation by the linear velocity of the relative motion. The acceleration vector is directed perpendicularly to the radius connecting the rotation axis with the center of gravity of the moving mass (Figure 1).

Thus, Coriolis force moment is numerically equal to the product of Coriolis acceleration by the mass and by the trajectory curvature radius. In relation to the load trolley of the crane, this moment is calculated as the product of Coriolis force by the outreach according to the following formula:

$$
M_{C o r}=2 m V \omega R \text {, }
$$

where: $m$ - mass of the load trolley with the load and the hook assembly; $V$ - relative velocity of trolley travel; $\omega-$ angular velocity of boom rotation; $R$ - outreach.

In order to assess the degree of impact of Coriolis acceleration on operation of the swing mechanism, calculation of motion combination impact (swing and outreach increase) for the starting period of this mechanism - by the example of Liebherr 380 EC-B 12 Litronic tower crane - was performed. The crane is equipped with the saddle jib with the maximum outreach of $75 \mathrm{~m}$. The controlled velocity of trolley travel is $0-120$ meters per minute. The boom rotation

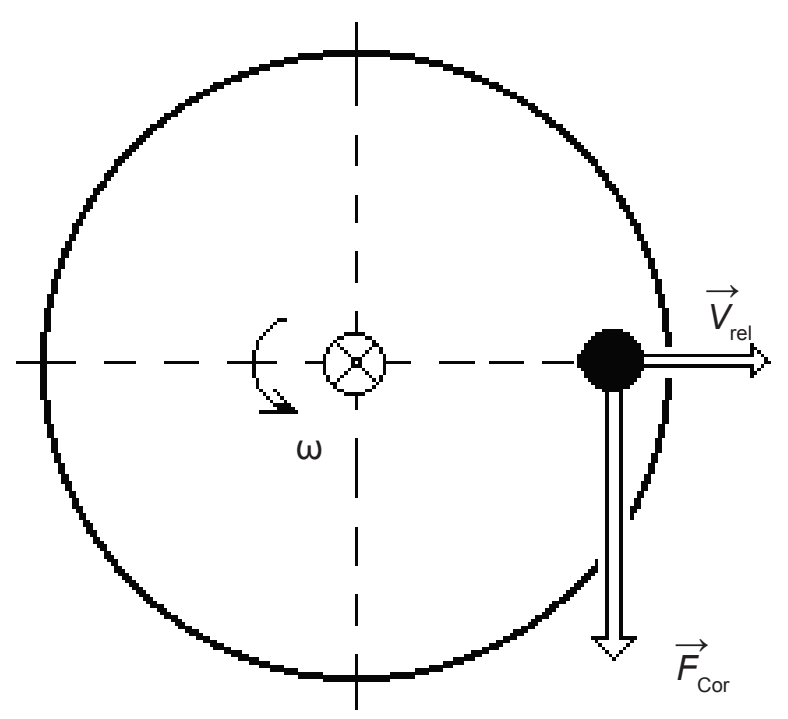

Figure 1. Coriolis force direction upon relative motion of the mass radially velocity is $0-0.8 \mathrm{rpm}$. The total power of electric motors of the swing mechanism is $15 \mathrm{~kW}$. Masses and overall dimensions of metal structures and other parts of the crane were taken from the website of the machine manufacturer (see http://www.liebherr.com/ CC/de-DE/region-RU/products_cc.wfw/id-13180-0/ measure-nonMetric).

The assumption, according to which the angular acceleration during the starting period changes according to the linear law from initial value $\varepsilon_{1}$ to final value $\varepsilon_{2}$, was made. Accordingly, the starting time is calculated as the ratio of the final angular velocity to the average angular acceleration:

$$
\mathrm{t}=\int_{0}^{\omega} \frac{1}{\varepsilon} d \omega=\frac{2 \omega}{\varepsilon_{1}+\varepsilon_{2}} .
$$

Angular accelerations are determined on the basis of the equation of traction balance as the abundance of the tractive effort torque $\left(M_{\text {tract }}-\Sigma M_{\text {resist }}\right)$, divided by total inertia moment $J_{\Sigma}$ of rotating parts:

$$
\varepsilon=\frac{M_{\text {tract }}-\Sigma M_{\text {resist }}}{\Sigma J} .
$$

The tractive effort torque of the frequencyregulated drive of the crane mechanism is assumed to be approximately constant during the whole starting period (Masandilov, 1998). The starting torque ratio is taken equal to two. The friction losses are taken into account by coefficient of efficiency $\eta=90 \%$.

$$
M_{\text {tract }}=\frac{N_{\mathrm{em}} \eta}{\omega_{\text {nom }}} .
$$

Generally, the total moment of resistance to the swing consists of moment of friction $M_{\mathrm{fr}}$ in the rotation crown, moment of wind loads $M_{\mathrm{w}}$ on the boom and cantilever with counterbalance, and moment $M_{\text {cor }}$ caused by Coriolis force. It is obvious that at the beginning of the starting period $M_{\text {cor }}$ is equal to zero, and further it increases to the maximum value proportionally to the change of the angular velocity and outreach. The moment of wind loads was considered to be constant during the whole starting period of the mechanism.

$$
\Sigma M_{\text {resist }}=M_{\mathrm{fr}}+M_{\mathrm{w}}+M_{\mathrm{Cor}} .
$$

The well-known methodology (Aleksandrov et al., 1985) was used to determine the moment of friction in the rotation crown in relation to the ball-bearing rotation crown OPU-7 (OP-2500) which is usually used in cranes of domestic production.

Total inertia moment $\Sigma J$ consists of constant inertia moments of the boom with the cantilever and with counterbalance, rotating masses of the drive $J_{\text {const' }}$, and of variable mass inertia moments of the load trolley $Q_{\text {trol }}$ moving along the boom, hook assembly $Q_{\mathrm{h}}$ and load $Q_{1}\left(J_{\text {var }}\right.$ depends on the outreach):

$$
\begin{gathered}
J_{\mathrm{var}}=\frac{Q_{\mathrm{trol}}+Q_{\mathrm{h}}+Q_{\mathrm{l}}}{R^{2}} ; \\
\Sigma J=J_{\text {const }}+J_{\mathrm{var}} .
\end{gathered}
$$


In view of the aforesaid, the starting process can be described by four dependencies:

$$
\begin{gathered}
\varepsilon_{1}=\frac{M_{\mathrm{tract}}-\mathrm{M}_{\mathrm{fr}}-M_{\mathrm{w}}}{J_{\text {const }}+J_{\mathrm{var}}} ; \\
\varepsilon_{2}=\frac{M_{\mathrm{tract}}-\mathrm{M}_{\mathrm{fr}}-M_{\mathrm{w}}-M_{\mathrm{Cor}}}{J_{\text {const }}+J_{\mathrm{var}}} ; \\
\mathrm{t}=\frac{2 \omega}{\varepsilon_{1}+\varepsilon_{2}} ; \\
R=R_{0}+V \mathrm{t},
\end{gathered}
$$

where $R_{0}$ is the outreach at the initial moment of the mechanism starting period.

Formula 7 is used upon calculation of $J_{\text {var }}$ and $M_{\text {Cor. }}$ After substitution of (7) in (1), and (3), (2) - in (4), (3) - in (4) and (5), (4) and (5) - in (6) and subsequent algebraic transformations, the abovementioned dependencies are reduced to the cubic polynomial with constant coefficients $A_{1}, A_{2}, A_{3}$, and $A_{4}$ :

$$
A_{1} \mathrm{t}^{3}+A_{2} \mathrm{t}^{2}+A_{3} \mathrm{t}+A_{4}=0 \text {. }
$$

Hence, the required starting time is calculated as the root of the cubic equation.

Two options of crane operation according to the load were subject to calculation:

1) load mass $Q=12,000 \mathrm{~kg}$, equal to the maximum safe working load, velocity of the load trolley $V=60$ meters per minute, equal to the half of the maximum value;

2) load mass $Q=6,000 \mathrm{~kg}$, equal to the half of the maximum safe working load, velocity of the load trolley $V=120$ meters per minute, maximum.

In both options, outreach at the initial moment of the starting period $R_{0}=7 \mathrm{~m}$, boom rotation velocity after starting is $0.8 \mathrm{rpm}$.

\section{Results}

The calculation results (Figure 2, Figure 3, Figure 4) indicate the impact of such factors as the velocity of trolley travel along the boom and wind load on starting parameters. The zero velocity means that the combination of motions does not happen and, therefore, Coriolis acceleration is absent. In the calculations, the direction of the wind load vector is accepted perpendicularly to the boom, which is the worst option creating the highest resistance to its swing.

\section{Conclusions}

The analysis of the presented results enables to draw the following conclusions:

1. The consideration of Coriolis acceleration at the starting of the crane swing mechanism upon combination of motions can change noticeably the calculation results of such parameters as starting period duration and angular acceleration at the final stage of the starting period. The increase of the starting time constituting the most part of the operating time of the swing mechanism can exceed $20 \%$.

\section{Load $=12 \mathrm{t}$}

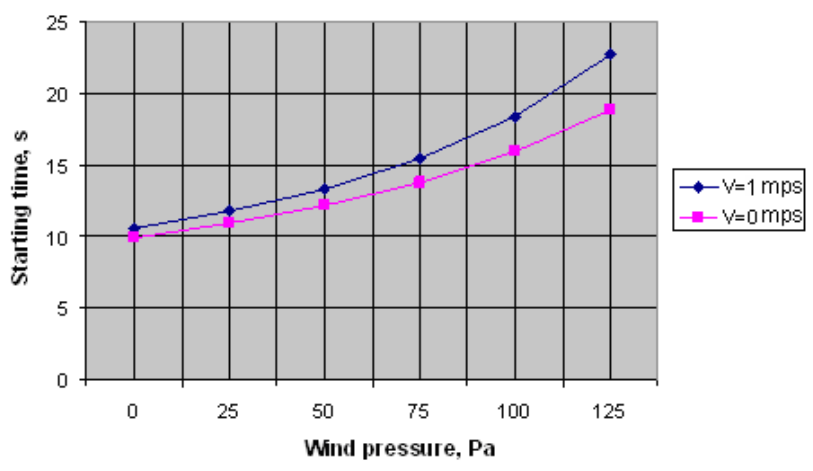

Figure 2. Swing mechanism starting time with a load of $12 \mathrm{t}$ under the conditions of various wind pressure intensities (upon combination of operations $(\mathrm{V}=1 \mathrm{mps})$ and without such combination ( $\mathrm{V}=0 \mathrm{mps})$ )

\section{Load $=6 \mathrm{t}$}

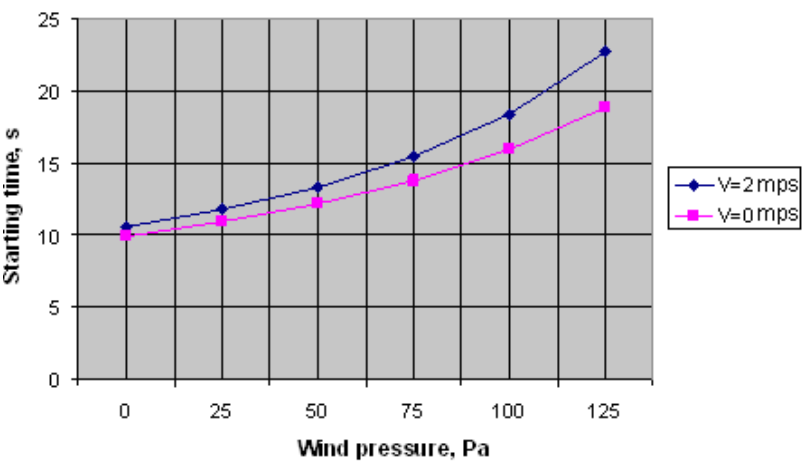

Figure 3. Swing mechanism starting time with a load of $6 t$ under the conditions of various wind pressure intensities (upon combination of operations $(\mathrm{V}=2 \mathrm{mps})$ and without such combination ( $\mathrm{V}=0 \mathrm{mps})$ )

Decrease in the angular acceleration

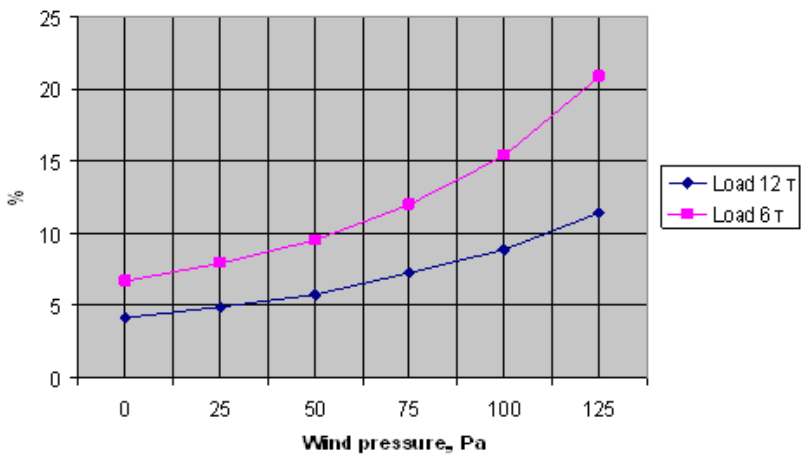

Figure 4. Relative decrease in the angular acceleration of the boom by the end of the starting period, caused by combination of operations under the conditions of various wind pressure intensities

2. The impact of Coriolis acceleration becomes significant upon adverse combination of two factors: high velocity of load trolley travel along the boom and high resistance to the swing caused by the wind 
load which is transversal to the metal structures of the boom.

3. It is necessary to take into account the Coriolis acceleration factor for tower cranes with high velocity of the trolley upon calculation of the swing mechanism capacity, and the corresponding issue is quite topical.

\section{References}

Aleksandrov, M. (1986). Gruzopodjemnye mashiny [Hoisting machines]. Moscow: Mechanical Engineering Publishing House. (in Russian)

Aleksandrov, M. et al. (1985). Podemno-transportnye mashiny [Carrying and lifting machines]. Moscow: Vysshaya Shkola Publishing House. (in Russian)

Gokhberg, M. (red.) (1988). Spravochnik po kranam, Ch. 1 Harakteristiki materialov i nagruzok. Osnovy rascheta kranov, ih privodov, i metallicheskih konstrukcij [Reference manual for cranes, Vol. 1 Characteristics of materials and loads. Fundamentals of calculation of cranes, crane drives and metal structures]. Moscow: Mechanical Engineering Publishing House. (in Russian)

Kholyavko, A., Kapralov, P., Bueva, A. (2014). Ustoichivost ekskavatorov [Stability of excavators]. In: sbornik materialov 10-i iubileinoi Vserossiiskoi nauchno-tekhnicheskoi konferentcii studentov, aspirantov i molodykh uchenykh s mezhdunarodnym uchastiem, posviashchennoi 80-letiiu obrazovaniia Krasnoiarskogo kraia [proceedings of the 10th anniversary All-Russian scientific and technical conference of students, postgraduate students and young scientists with the international participation, devoted to the 80th anniversary of the foundation of Krasnoyarsk Territory]. Krasnoyarsk: Siberian Federal University. (in Russian)

Kolesnikov, P., Moiseev, G. (2013). Uchet koriolisovykh sil inertcii pri proektirovanii tekhnologicheskogo oborudovaniia povorotnykh lesopogruzchikov [Consideration of Coriolis forces of inertia upon design of the technological equipment for swinging log loaders]. New materials and technologies in mechanical engineering, 18, pp. 151-153. (in Russian)

La Duc, V. (2015). Crane sway reduction using Coriolis force produced by radial spring and damper. Journal of Mechanical Science and Technology, 29(3), pp 973-979.

Masandilov, L. (1998). Jelektroprivod podjemnyh kranov [Electric drive of hoisting cranes]. Moscow: Publishing House of the Moscow Power Engineering Institute. (in Russian)

Perig, A., Stadnik, A., Matveev, I. (2011). O dinamicheskikh rezhimakh raboty strelovogo krana pri postoiannom ugle vyleta strely [About dynamic operating modes of the boom crane at the constant angle of the boom outreach]. Bulletin of the Donbass State Engineering Academy, 4 (25), pp. 234-239. (in Ukrainian)

Polyakhov, N. et al. (2015). Teoreticheskaja mehanika [Theoretical mechanics]. Moscow: Urait. (in Russian)

Teplyakov, A. (2004). Realizatciia optimalnogo upravleniia chastotnym elektroprivodom mekhanizma povorota [Implementation of the optimum control of the variable-frequency electric drive of the swing mechanism]. Elektromashinobudovannia ta elektroobladannia [Electric Machine Industry and Electrical Equipment], 62, pp. 36-39. (in Ukrainian)

Uchiyama, N. (2013). Simple rotary crane dynamics modeling and open-loop control for residual load sway suppression by only horizontal boom motion. Mechatronics, 23(8), pp. 1223-1236.

Vainson, A. (1989). Podjemno-transportnye mashiny [Carrying and lifting machines]. Moscow: Mechanical Engineering Publishing House. (in Russian) 